\title{
Effects of Leymus chinensis replacement with whole-crop wheat hay on blood parameters, fatty acid composition, and microbiomes of Holstein bulls
}

\author{
Wenjing Niu, ${ }^{*}$ Yang He, ${ }^{*}$ Haibo Wang, ${ }^{*}$ Chuanqi Xia, ${ }^{*}$ Haitao Shi, $†$ Binghai Cao, ${ }^{* 1}$ and Huawei Su*1 \\ *State Key Laboratory of Animal Nutrition, College of Animal Science and Technology, China Agricultural University, Beijing, 100193, P. R. China \\ †Department of Animal and Poultry Science, College of Agriculture and Bioresources, University of Saskatchewan, Saskatoon, SK, \\ S7N 5A8, Canada
}

\begin{abstract}
This study investigated the replacement of Leymus chinensis (LC) with whole-crop wheat hay (WCWH) in the diets of Holstein bulls in the fattening stage and examined the potential effects on blood parameters, fatty acids in rumen fluid and serum, and the rumen microbiomes. In this study, 12 Holstein bulls in the fattening period (body weight $=485.0 \pm 40.8$ $\mathrm{kg}$ ) were assigned to 1 of 4 dietary treatments using a $4 \times 4$ Latin square design. Each experimental period consisted of a 17-d adaptation period and a 5-d collection period. The dietary treatments consisted of 4 proportions of WCWH $(0,33,67$, and $100 \%)$ as a substitute for LC (designated as WCWH0, WCWH33, WCWH67, and WCWH100, respectively). On d 18 and 22 of each experiment period, blood and rumen content samples were collected for analysis, respectively. Realtime quantitative PCR was used to analyze the rumen microbiomes. The results from this study revealed no differences in the saturated, monounsaturated, and polyunsaturated long-chain fatty acid proportions of rumen liquid among the treatments. It was observed in the present trial that rumen microbiotal flora were not significantly different in the bulls fed LC compared with the bulls fed WCWH. Additionally, blood sample analysis demonstrated that the concentration of urea nitrogen in the WCWH100 group was higher than that observed in the other groups. Meanwhile, no differences were detected for other serum parameters. There were no differences in the proportions of serum saturated, monounsaturated, and polyunsaturated long-chain fatty acids among the treatments. In conclusion, our data revealed that LC can be replaced with WCWH in the diet of Holstein bulls in the fattening stage with
\end{abstract}

\footnotetext{
Received May 31, 2017.

Accepted August 3, 2017.

${ }^{1}$ Corresponding authors: caobhchina@163.com and suhuawei@cau. edu.cn
}

no negative effects on the blood indicators, fatty acids, and microbiomes.

Key words: Holstein bull, blood parameter, fatty acid, microbiome

\section{INTRODUCTION}

Leymus chinensis (LC), commonly known as Chinese wildrye, is a native, cool-season perennial species of Gramineae that is mainly distributed in the Eurasian Steppe, including the eastern Inner Mongolian Plateau and the Songnen Plain in China (Chen et al., 2013). However, regions such as North and Central China have limited LC production. Livestock farms of these regions have to buy LC and transport the LC over long distances. Therefore, in the ruminant industry, it is necessary to explore alternative roughage sources to avoid the high line-haul expenses of LC.

Wheat is cultivated as one of the principal crops, and wheat straw is a plentiful agricultural residue (Kim and Dale, 2004; Shi and Yu, 2017). However, most of the wheat straw is burned, which results in not only severe resource waste but also air pollution such as particulate matter (Li et al., 2008; Talebnia et al., 2010). Therefore, it would be greatly beneficial and significant to fully use the wheat straw residue. Applications of agronomy and plant breeding methods for the production of whole-crop wheat ( $\mathbf{W C W})$, together with its potentially lower production cost, have resulted in the increased use of this crop as feed for ruminants (Walsh et al., 2009). For ruminants, ingestion of WCW, which consists of wheat straw and wheat grain, has greater nutrient content and higher feed efficiency than ingestion of wheat straw alone. Several studies have shown that fermented WCW can increase DMI and improve rumen fermentation in beef cattle (Keady et al., 2007; Owens et al., 2009). Weinberg and Chen (2013) reported that prolonging the storage period of WCW may result in decreased digestibility values of NDF and DM. Furthermore, it was reported that the increased 
ratios of grain to straw plus chaff of WCW ensilage in the diets can abate enteric methane emission in finishing beef steers (Mc Geough et al., 2010). Therefore, replacement of whole-crop wheat hay $(\mathbf{W C W H})$ is greatly important and urgently necessary. Not only can this switch conserve energy and reduce pollution, but it can also contribute to the combination of agriculture and animal husbandry.

Different forages may have an effect on rumen fermentation and rumen microbes (Zhu et al., 2013). Results from previous research have revealed that inclusion of $5 \% \mathrm{NaOH}$-treated corn straw as a substitute for wheat hay in the TMR of lactating cows had a significant effect on the bacterial community within the rumen (Jami et al., 2014). It is commonly known that fatty acid composition in the rumen is influenced by changes in dietary fatty acids via the rumen microbiome, such as increased SFA due to biohydrogenation of dietary UFA (Toral et al., 2011). Moloney et al. (2013) reported that there was no difference in the fatty acid composition of intramuscular lipids when grass silage was replaced with WCW silage in beef cattle. Furthermore, changes in diet can alter blood metabolites, including the biochemical index and fatty acid composition of blood (Szkudelska et al., 2016). A previous study had shown that a partial replacement of LC with corn stover in lactation diets did not negatively affect the blood metabolites of dairy cows (Shi et al., 2015). However, there is little published information on the effects of WCWH as an LC replacement. Therefore, we tested several blood parameters, fatty acid composition of rumen liquid and serum, and the microbiomes of Holstein bulls who were exposed to a changed diet. It could be hypothesized that WCWH may replace LC in the diets of finishing dairy bulls without having a negative effect. The objectives of the trial were to study the effects of WCWH as a substitute for LC on blood parameters, rumen fatty acid, and microbial flora in Holstein bulls.

\section{MATERIALS AND METHODS}

This study was performed in accordance with the approved Regulations for the Administration of Affairs Concerning Experimental Animals (The State Science and Technology Commission of P. R. China, 1988). The experimental procedures were approved by the Animal Welfare and Ethics Committee of China Agricultural University (permit no. DK1008).

\section{Animals, Diets, and Experimental Procedure}

The feeding experiment was conducted at the Xinzhicheng Dairy Farm (Zhuozhou City, Hebei Prov- ince, China). Approximately $15 \mathrm{t}$ of $\mathrm{WCW}$ was reaped from nearby farmland at the milky ripe stage. The height of the wheat stubble was 10 to $15 \mathrm{~cm}$. Next, the WCW was carefully dried by the sun and kept for the feeding trial. Approximately $20 \mathrm{t}$ of $\mathrm{LC}$ was acquired from Northeast China through line haul.

Twelve Holstein bulls $(\mathrm{BW}=485.0 \pm 40.8 \mathrm{~kg})$ were assigned to 1 of 4 dietary treatments using a $4 \times 4$ Latin square design. The experimental diets comprised $45 \%$ roughage and $55 \%$ concentrate and included 4 dietary conditions of $\mathrm{WCWH}(0,33,67$, and 100\%) as a substitute proportion of LC. All diets met NRC (2000) requirements and were designed to be isocaloric and isonitrogenous. Dietary ingredients and nutrient compositions for the trial are shown in Table 1. The nutrient compositions of $\mathrm{LC}$ and $\mathrm{WCWH}$ are shown in Table 2. Dietary fatty acid composition is presented in Table 3. Each experimental period consisted of $17 \mathrm{~d}$ of diet adaptation and $5 \mathrm{~d}$ of sample collection. Then, the bulls were vaccinated, expelled of worms, weighed, and tagged using numbered tickets before starting the experiment. Animals were offered experimental diets twice daily at 0700 and $1700 \mathrm{~h}$ and had access to water ad libitum. The amount of feed was adjusted every 3 to $4 \mathrm{~d}$, permitting 5 to $10 \%$ residues.

\section{Sampling}

Between d 18 and 22 of each experimental period, the forage and residues were collected. All feed samples were dried at $65^{\circ} \mathrm{C}$ for $48 \mathrm{~h}$ in the oven, ground through a 1-mm screen using a Wiley mill (A. H. Thomas Co., Philadelphia, PA), and kept at $-20^{\circ} \mathrm{C}$ until analysis for $\mathrm{DM}, \mathrm{OM}, \mathrm{CP}$, ether extract, NDF, and ADF.

On d 18 of each experimental period, blood was obtained via the jugular vein into $10-\mathrm{mL}$ evacuated serum tubes before the morning feeding. Serum samples were obtained after the tubes were centrifuged at 3,000 $\times g$ at $4^{\circ} \mathrm{C}$ for $20 \mathrm{~min}$. Next, the serum was separated into 3 aliquots and kept at $-20^{\circ} \mathrm{C}$ for biochemical indicators and long-chain fatty acid (LCFA) analysis.

Approximately $100 \mathrm{~mL}$ of rumen samples was collected using an esophageal tube $2 \mathrm{~h}$ after the morning feeding on d 22 of each experimental period. Three aliquots of $10-\mathrm{mL}$ samples were taken and stored at $-20^{\circ} \mathrm{C}$ for LCFA analysis. Three aliquots of $1-\mathrm{mL}$ samples were stored in liquid nitrogen for analysis of the rumen microbiomes.

\section{Analytical Procedures}

Chemical Composition. The DM and ash of feed samples were determined according to methods 934.01 
NIU ET AL.

Table 1. Ingredients and nutrient compositions of the dietary treatments

\begin{tabular}{|c|c|c|c|c|}
\hline \multirow[b]{2}{*}{ Item } & \multicolumn{4}{|c|}{ Diet $^{1}$} \\
\hline & WCWH0 & WCWH33 & WCWH67 & WCWH100 \\
\hline \multicolumn{5}{|l|}{ Ingredient, $\%$ on DM basis } \\
\hline Corn grain & 22.3 & 24.1 & 25.9 & 27.6 \\
\hline Wheat grain & 26.5 & 23.8 & 21.1 & 18.5 \\
\hline Soybean meal & 3.45 & 2.31 & 1.14 & 0.00 \\
\hline Rapeseed meal & 0.70 & 1.54 & 2.39 & 3.23 \\
\hline Wheat bran & 0.00 & 1.14 & 2.32 & 3.47 \\
\hline $\mathrm{NaHCO}_{3}$ & 0.55 & 0.55 & 0.55 & 0.55 \\
\hline $\mathrm{NaCl}$ & 0.55 & 0.55 & 0.55 & 0.55 \\
\hline Limestone & 0.44 & 0.48 & 0.51 & 0.55 \\
\hline Mineral-vitamin premix ${ }^{2}$ & 0.55 & 0.55 & 0.55 & 0.55 \\
\hline Whole-crop wheat hay & 0.00 & 14.9 & 30.2 & 45.0 \\
\hline Leymus chinensis & 45.0 & 30.2 & 14.9 & 0.00 \\
\hline \multicolumn{5}{|c|}{ Chemical composition, $\%$ on DM basis } \\
\hline $\mathrm{OM}$ & 94.0 & 92.8 & 91.8 & 91.1 \\
\hline $\mathrm{CP}$ & 12.1 & 12.2 & 12.2 & 12.1 \\
\hline TDN & 76.9 & 76.9 & 77.0 & 77.0 \\
\hline Ether extract & 1.89 & 1.95 & 1.99 & 2.03 \\
\hline NDF & 31.9 & 29.9 & 27.9 & 25.9 \\
\hline $\mathrm{ADF}$ & 17.5 & 16.6 & 15.7 & 14.9 \\
\hline
\end{tabular}

${ }^{1}$ WCWH0 $=0 \%$ of Leymus chinensis was replaced by whole-crop wheat hay; WCWH33 $=33 \%$ of Leymus chinensis was replaced by whole-crop wheat hay; WCWH67 $=67 \%$ of Leymus chinensis was replaced by wholecrop wheat hay; WCWH100 $=100 \%$ of Leymus chinensis was replaced by whole-crop wheat hay.

${ }^{2}$ Every kilogram of mineral-vitamin premix contained 3,500 IU of vitamin A, 3,000 IU of vitamin $\mathrm{D}_{3}, 45 \mathrm{IU}$ of vitamin E, $63 \mathrm{mg}$ of $\mathrm{Zn}, 60 \mathrm{mg}$ of Fe, $98.6 \mathrm{mg}$ of $\mathrm{Mn}, 20 \mathrm{mg}$ of $\mathrm{Cu}, 1.1 \mathrm{mg}$ of I, $0.50 \mathrm{mg}$ of Se, and $0.45 \mathrm{mg}$ of Co.

and 924.05 of AOAC (1990), respectively. The content of OM was calculated as the total percentage (100\%) minus the ash content. The $\mathrm{CP}$ was analyzed by the Kjeldahl method (AOAC, 1990; method 990.03) using a Kjeldahl nitrogen determination apparatus (Kjeltec 2100, Foss, Hillerød, Denmark). The ether extract was determined in accordance with AOAC (1990) method 920.39 using an AnkomXT15 Extractor (Ankom Technology, Fairport, NY). The Ankom fiber analyzer (Ankom Technology) was used to examine ADF and NDF according to the method described by Van Soest et al. (1991), and $\alpha$-amylase and sodium sulfite were used for the NDF procedure.

Blood Analysis. The biochemical indicators of serum were analyzed using a clinical autoanalyzer (Hitachi 7020; Hitachi Co., Tokyo, Japan). The concentrations of glucose, triglyceride, total protein, urea ni-

Table 2. Chemical composition of Leymus chinensis (LC) and wholecrop wheat hay (WCWH)

\begin{tabular}{lrc}
\hline Item & LC & WCWH \\
\hline DM, \% & 93.86 & 92.67 \\
OM, \% of DM & 94.08 & 88.20 \\
CP, \% of DM & 5.87 & 11.18 \\
Ether extract, \% of DM & 2.24 & 2.23 \\
NDF, \% of DM & 70.66 & 57.44 \\
ADF, \% of DM & 38.78 & 32.97 \\
Hemicellulose, \% of DM & 31.88 & 24.47 \\
\hline
\end{tabular}

trogen, and BHB were measured using glucose oxidase, glycerophosphate oxidase, biuret, urease, and hydroxybutyric acid dehydrogenase, respectively, applying the commercial test kits according to the manufacturer's instructions (Jiuqiang Bio-Technique Co., Beijing, China). The total cholesterol, albumin, high-density lipoprotein cholesterol (HDL-C), and low-density lipoprotein cholesterol (LDL-C) concentrations in serum were analyzed using an enzymatic method, a bromocresol green method, and a direct measurement method, respectively.

Fatty Acid Analysis. The LCFA composition in rumen and serum samples was quantified through a gas chromatograph (GC-2014; Shimadzu Corp., Kyoto, Japan) fitted with a hydrogen flame detector and a 100-m capillary column (HP-88, 0.5-mm i.d., 0.20- $\mu \mathrm{m}$ film; Agilent Technologies, Santa Clara, CA). Margaric acid (C17:0; Sigma-Aldrich Co. LLC, St. Louis, MO) was used as an internal standard. The oven temperature protocol was as follows. Samples were incubated at $160^{\circ} \mathrm{C}$ for $2 \mathrm{~min}$; then the temperature was increased to $220^{\circ} \mathrm{C}$ at a rate of $5^{\circ} \mathrm{C} / \mathrm{min}$ and maintained for $30 \mathrm{~min}$. Helium was used as a carrier gas at a flow rate of $2 \mathrm{~mL} /$ min. A flame ionization detector was used with an air and hydrogen flow of 450 and $40 \mathrm{~mL} / \mathrm{min}$, respectively. Both injector and detector temperatures were set to $280^{\circ} \mathrm{C}$.

The injection volume was $1 \mu \mathrm{L}$. Sample fatty acids were identified by comparing the relative retention 
Table 3. Fatty acid compositions of the dietary treatments (\% of total FA)

\begin{tabular}{|c|c|c|c|c|}
\hline \multirow[b]{2}{*}{ Fatty acid } & \multicolumn{4}{|c|}{$\operatorname{Diet}^{1}$} \\
\hline & WCWH0 & WCWH33 & WCWH67 & WCWH100 \\
\hline \multicolumn{5}{|l|}{ Saturated } \\
\hline C14:0 & 2.76 & 2.14 & 1.46 & 0.75 \\
\hline C15:0 & 0.37 & 0.32 & 0.27 & 0.23 \\
\hline $\mathrm{C} 16: 0$ & 19.80 & 21.29 & 22.05 & 22.01 \\
\hline $\mathrm{C} 18: 0$ & 3.48 & 3.14 & 2.64 & 2.02 \\
\hline $\mathrm{C} 20: 0$ & 0.75 & 0.64 & 0.54 & 0.44 \\
\hline \multicolumn{5}{|l|}{ Monounsaturated } \\
\hline $\mathrm{C} 14: 1$ & 0.12 & 0.20 & 0.29 & 0.37 \\
\hline $\mathrm{C} 15: 1$ & 0.14 & 0.14 & 0.14 & 0.15 \\
\hline C16:1 & 0.98 & 0.81 & 0.63 & 0.44 \\
\hline C18:1n-9 trans & 0.71 & 0.46 & 0.23 & 0.03 \\
\hline $\mathrm{C} 18: 1 \mathrm{n}-9$ cis & 27.12 & 24.89 & 21.92 & 18.41 \\
\hline $\mathrm{C} 20: 1$ & 6.41 & 6.37 & 6.27 & 6.13 \\
\hline $\mathrm{C} 24: 1$ & 0.21 & 0.25 & 0.26 & 0.25 \\
\hline \multicolumn{5}{|l|}{ Polyunsaturated } \\
\hline C18:2n- 6 trans & 0.52 & 0.55 & 0.56 & 0.54 \\
\hline $\mathrm{C} 18: 2 \mathrm{n}-6$ cis & 34.22 & 36.18 & 39.98 & 45.39 \\
\hline $\mathrm{C} 20: 2$ & 0.13 & 0.19 & 0.24 & 0.26 \\
\hline $\mathrm{SFA}^{2}$ & 28.66 & 29.21 & 28.72 & 27.23 \\
\hline $\mathrm{UFA}^{3}$ & 71.34 & 70.79 & 71.28 & 72.77 \\
\hline MUFA $^{4}$ & 35.70 & 33.12 & 29.74 & 25.78 \\
\hline $\mathrm{PUFA}^{5}$ & 35.65 & 37.67 & 41.53 & 46.99 \\
\hline
\end{tabular}

${ }^{1}$ WCWH0 $=0 \%$ of Leymus chinensis was replaced by whole-crop wheat hay; WCWH33 $=33 \%$ of Leymus chinensis was replaced by whole-crop wheat hay; WCWH67 $=67 \%$ of Leymus chinensis was replaced by wholecrop wheat hay; WCWH100 $=100 \%$ of Leymus chinensis was replaced by whole-crop wheat hay.

${ }^{2} \mathrm{C} 14: 0, \mathrm{C} 15: 0, \mathrm{C} 16: 0, \mathrm{C} 18: 0, \mathrm{C} 20: 0, \mathrm{C} 21: 0, \mathrm{C} 22: 0, \mathrm{C} 23: 0, \mathrm{C} 24: 0$.

${ }^{3} \mathrm{C} 14: 1, \mathrm{C} 15: 1, \mathrm{C} 16: 1$, cis-9 C18:1, trans-9 C18:1, C20:1, C24:1, cis-6 C18:2, trans-6 C18:2, C18:3n-3, C20:2, C20:3n-6, C22:6n-3.

${ }^{4} \mathrm{C} 14: 1, \mathrm{C} 15: 1, \mathrm{C} 16: 1$, cis-9 C18:1, trans-9 C18:1, C20:1, C24:1.

${ }^{5}$ cis-6 C18:2, trans-6 C18:2, C18:3n-3, C20:2, C20:3n-6, C22:6n-3.

times with methyl ester standard mixtures (SigmaAldrich Co. LLC), and the relative proportions were determined as percentages of summed peak areas. Fatty acids were expressed in gravimetric concentration, and the content of fatty acids is shown as the ratio of all tested fatty acids.

DNA Extraction and Real-Time Quantitative $\boldsymbol{P C R}$. The rumen samples $(1.5 \mathrm{~mL})$ were centrifuged at $1,000 \times g$ for $10 \mathrm{~min}$ at $4^{\circ} \mathrm{C}$, and the sediment was discarded. The samples were then centrifuged at 12,000 $\times g$ for $10 \mathrm{~min}$ at $4^{\circ} \mathrm{C}$ to remove the clear supernatant extract. Soon afterward, the DNA was extracted from the rumen samples using the DNA kit (Omega Bio-Tek, Norcross, GA) in line with the protocol of the manufacturer. A spectrophotometer (UV-1700, Shimadzu Corp.) was used to evaluate the DNA concentration and purity at the optical density of 260 and $280 \mathrm{~nm}$.

The primer sequences to amplify the total bacteria, fungi, methanogens, protozoa, Ruminococcus flavefaciens, Fibrobacter succinogenes, Butyrivibrio fibrisolvens, Streptococcus bovis, Prevotella bryantii, and Ruminobacter amylophilus are shown in Table 4. Primer pairs of P. bryantii and R. amylophilus for quantitative analysis were designed using Primer 5 software. The real-time quantitative PCR was performed using Stratagene MX3000p (Agilent Technologies) with fluorescence detection of SYBR green dye. Agilent Technologies software was used to analyze the real-time quantitative PCR assay.

The PCR reaction mixture comprised $10.0 \mu \mathrm{L}$ of SYBR Premix Ex Taq (FS Universal SYBR Green Master ROX, Roche Diagnostics GmbH, Mannheim, Germany), 1.6 $\mu \mathrm{L}$ of each primer (concentration $=10.0$ $\mu \mathrm{mol} / \mathrm{L}$ ), $7.4 \mu \mathrm{L}$ of sterile distilled water, and $1.0 \mu \mathrm{L}$ of DNA template. The amplification parameters were as follows: 1 hold cycle for initial denaturation and activation of the hot-start polymerase system at $95^{\circ} \mathrm{C}$ for 5 min, then 40 cycles of $95^{\circ} \mathrm{C}$ for $15 \mathrm{~s}$, annealing at $60^{\circ} \mathrm{C}$ for $30 \mathrm{~s}$, and extension at $72^{\circ} \mathrm{C}$ for $30 \mathrm{~s}$. To confirm the specificity of the primers, a melting curve of PCR products was monitored by slow heat from 60 to $95^{\circ} \mathrm{C}$ at $1^{\circ} \mathrm{C} / \mathrm{s}$, with fluorescence collection at $1^{\circ} \mathrm{C}$ intervals. To calculate the PCR efficiency, standard curves were established by amplification of a 10-fold dilution series ( $\mathrm{n}=5$ dilutions) of the PCR product of 1 rumen sample. The 5 dilution points displayed a linear cor- 
relation between the threshold cycle value and the log of DNA concentration, and the standard curves were generated. The obtained standard curves satisfied the requirement criteria of efficiency $\left(\mathrm{R}^{2}>0.99 ; 90 \%<\right.$ efficiency $<110 \%$ ). The amplification efficiencies of each primer set were almost identical, demonstrating that the target DNA was amplified at similar efficiencies irrespective of the existence of nontarget DNA. The PCR efficiency for each primer pair was calculated using the slope of the standard curve depending on the formula

$$
\text { efficiency }=10^{(1 /- \text { slope })}-1 .
$$

The abundance of microbes was represented as the proportion of total bacteria according to the formula (Livak and Schmittgen, 2001)

$$
\text { proportion of target }=2^{-(\mathrm{Ct} \text { target }-\mathrm{Ct} \text { total bacteria })} \text {, }
$$

where Ct represents the threshold cycle.

\section{Statistical Analyses}

All data were statistically analyzed using PROC MIXED in SAS 9.0 (SAS Institute Inc., Cary, NC). The model used for the analysis was

$$
\mathrm{Y}=\mu+\mathrm{Ti}+\mathrm{Pj}+\mathrm{Ck}+\mathrm{eijk}
$$

where $\mathrm{Y}$ is the observation of cattle, $\mu$ is the overall mean, $\mathrm{Ti}$ is the fixed effect of treatment $(\mathrm{i}=1,2,3$, or
4), $\mathrm{Pj}$ is the fixed effect of period ( $\mathrm{j}=1,2,3$, or 4$), \mathrm{Ck}$ is the fixed effect of cattle, and eijk is the residual error. All of the data fell in the normal distribution, which was performed using the Shapiro-Wilk test in SAS 9.0. Duncan's multiple range test was used to determine the differences between treatments. Differences were considered significant at $P<0.05$. Orthogonal contrast was also conducted to evaluate linear and quadratic effects of treatments.

\section{RESULTS AND DISCUSSION}

\section{Rumen Microbiome}

The results of the rumen microbiome analysis are listed in Table 5. Bulls that were fed LC replaced with WCWH did not have significant differences in rumen microbial flora in the present trial $(P>0.05)$. Generally, diet is the main determinant of rumen microbe composition ( $\mathrm{Li}$ et al., 2016). In the present research, the 4 treatments had the same ratio of concentrate to forage, the diets contained similar levels of energy and protein, and the experimental animals were kept under the same ambient conditions. This approach may account for the similarities in the rumen microbe population in bulls that have had their diet switched from LC to WCWH. Similarly, no changes were observed in the proportion of rumen protozoa and methanogens among groups in the study $(P>0.05)$. This may be due to a lack of change in the abundance of protozoa, as rumen methanogens are related to the protozoa (Zhang et al.,

Table 4. Polymerase chain reaction primers for quantitative PCR assay

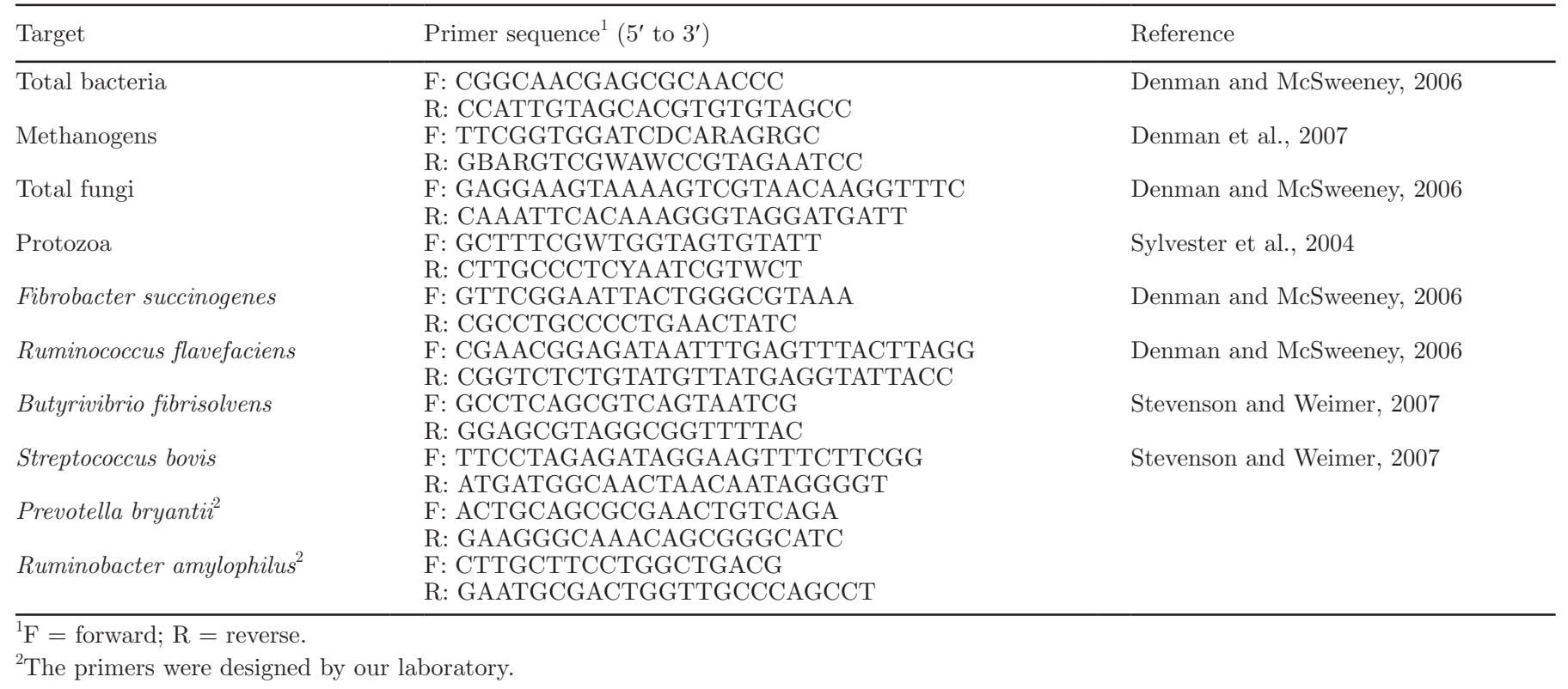


2015). Methanogens are strictly anaerobic Archaea in the rumen that are attached to rumen protozoa and feed pellets; they are adhered to the rumen epithelium and are associated as endosymbionts within the rumen protozoa (Janssen and Kirs, 2008). Both protozoa and methanogens are involved in the formation of $\mathrm{CH}_{4}$ in the rumen (Whitelaw et al., 1984).

We observed no significant differences in the relative abundance of $R$. flavefaciens and $F$. succinogenes in the rumen among the 4 treatments $(P>0.05)$. Ruminococcus flavefaciens is a powerful bacteria that can generate hemicellulase and cellulase to degrade plant fiber (Wood et al., 1982). Fibrobacter succinogenes is also one of the most highly cellulolytic species in the gastrointestinal tracts of ruminants (Kobayashi et al., 2008). The abundance of $R$. flavefaciens and F. succinogenes should not be different among the groups, which is expected because fiber digestibility was similar when bulls were fed WHCH as a substitute for LC (Niu et al., 2017). Butyrivibrio fibrisolvens is a type of fibrolytic bacteria that is important for the utilization of maltose and sucrose to produce butyrate (Fernando et al., 2010). A recent study determined that there was no difference in butyrate concentration in the rumens of bulls that were fed WHCH as a substitute for LC (Niu et al., 2017). Streptococcus bovis, which predominates during lactic acidosis, is a type of facultative anaerobe (Owens et al., 1998). There was no difference in the rapid growth of $S$. bovis when animals were fed a forage diet (Nagaraja and Titgemeyer, 2007). Our previous study showed that the rumen $\mathrm{pH}$ is similar among bulls fed WCWH and bulls fed LC (Niu et al., 2017). This finding suggests that the proportion of $S$. bovis was consistent among the groups and that $S$. bovis can inhibit ruminal acidosis in the rumen of bulls that have been switched to WCWH from LC. Overall, we conclude that switching the diet of feeding bulls from
LC to WCWH did not significantly affect the rumen microbial flora in the present study.

\section{Rumen LCFA Composition}

The results of LCFA composition analysis in the rumen are listed in Table 6 . We observed no differences in the SFA and UFA proportions of rumen liquid $(P$ $>0.05$ ) among the treatments, which was expected because of the similar SFA and UFA proportions in the diets. The rumen lipid metabolism is involved in lipolysis of dietary phospholipids, glycolipids, and triglycerides and is involved in the transformation from UFA to SFA through microbial biohydrogenation (Lourenço et al., 2010). The SFA proportion was similar among the groups, indicating that the fatty acids in both the LC and WCWH diet groups were subjected to a similar degree of substrate isomerization and biohydrogenation in the rumen (Yan et al., 2011). After fermentation, replacement of LC with WCWH did not significantly affect the C16:0 proportion of rumen liquid $(P>0.05)$, which was expected because there were similar C16:0 proportions among the diet groups. Replacement of LC with WCWH did not affect the proportion of C18:0, $\mathrm{C} 18: 1$, and $\mathrm{C} 18: 3 \mathrm{n}-3$ in the rumen $(P>0.05)$. The $\mathrm{C} 18: 0$ is related to ruminal biohydrogenation of dietary PUFA. Through the isomerization of the cis-12 bond to either the D11 or the D13 position, C18:3n-3 is initially metabolized to C18:0. Then, the bonds are hydrogenated to produce a C18:1 intermediate, and hydrogenation of the $\mathrm{C} 18: 1$ results in a final product of $\mathrm{C} 18: 0$ (Wilde and Dawson, 1966).

We observed no significant difference in the linoleic acid (C18:2) proportion of rumen liquid among treatments groups $(P>0.05)$. According to Mann and Truswell (2007), C18:2 is known as an essential fatty acid that must be supplied by the diet. However, the

Table 5. Effects of dietary treatments on rumen microbial flora (\% of total bacteria)

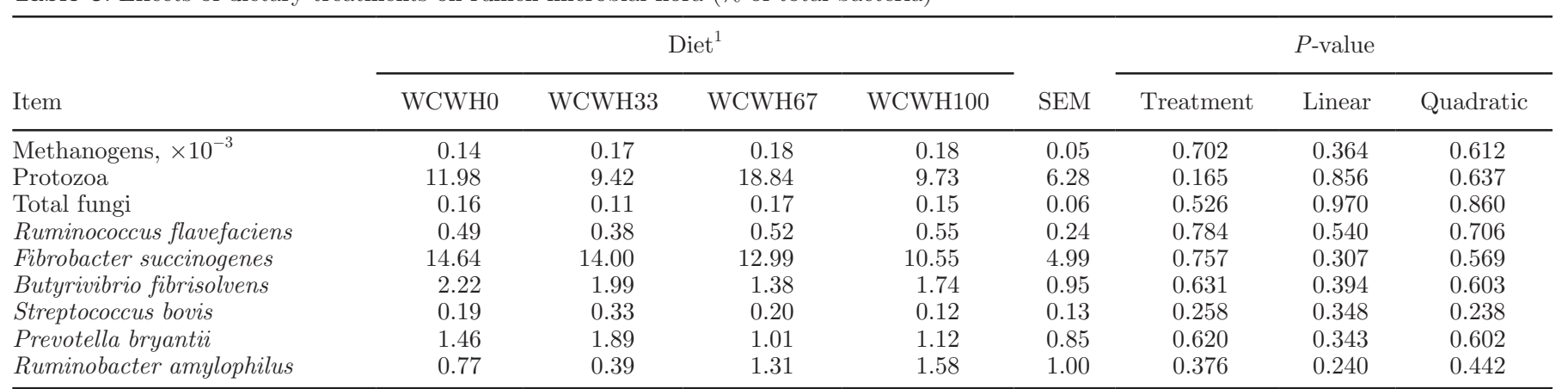

${ }^{1}$ WCWH0 $=0 \%$ of Leymus chinensis was replaced by whole-crop wheat hay; WCWH33 = 33\% of Leymus chinensis was replaced by whole-crop wheat hay; WCWH67 $=67 \%$ of Leymus chinensis was replaced by whole-crop wheat hay; WCWH100 $=100 \%$ of Leymus chinensis was replaced by whole-crop wheat hay. 
Table 6. Effect of dietary treatments on long-chain fatty acid composition of rumen sample (\% of total FA)



${ }^{1}$ WCWH0 $=0 \%$ of Leymus chinensis was replaced by whole-crop wheat hay; WCWH33 $=33 \%$ of Leymus chinensis was replaced by whole-crop wheat hay; WCWH67 $=67 \%$ of Leymus chinensis was replaced by whole-crop wheat hay; WCWH100 $=100 \%$ of Leymus chinensis was replaced by whole-crop wheat hay.

${ }^{2} \mathrm{C} 14: 0, \mathrm{C} 15: 0, \mathrm{C} 16: 0, \mathrm{C} 18: 0, \mathrm{C} 20: 0, \mathrm{C} 21: 0, \mathrm{C} 22: 0, \mathrm{C} 23: 0, \mathrm{C} 24: 0$.

${ }^{3} \mathrm{C} 14: 1, \mathrm{C} 15: 1$, C16:1, cis-9 C18:1, trans-9 C18:1, C20:1, C22:1n-9, C24:1, cis-6 C18:2, trans-6 C18:2, C18:3n-3, C18:3n-6, C20:2, C20:3n-3, C20:3n-6, C20:4 n-6, C20:5n-3, C22:2, C22:6 n-3.

${ }^{4} \mathrm{C} 14: 1, \mathrm{C} 15: 1, \mathrm{C} 16: 1$, cis-9 C18:1, trans-9 C18:1, C20:1, C22:1n-9, C24:1.

${ }^{5}$ cis-6 C18:2, trans-6 C18:2, C18:3n-3, C18:3n-6, C20:2, C20:3n-3, C20:3n-6, C20:4n-6, C20:5n-3, C22:2, C22:6n-3.

WCWH100 diet group had a greater proportion of C18:2 than other groups. This finding was probably attributable to a greater extent of ruminal biohydrogenation via microbes in the metabolite process of C18:2 in the Holstein bulls offered WCWH versus LC (Campidonico et al., 2016). We also determined that the changes in diets did not significantly change the MUFA and PUFA proportions in the rumen $(P>0.05)$. It has been reported that consumption of n-3 PUFA benefits human health; notably, it can reduce the incidence of hypertension, cardiovascular diseases, and arthritis (Simopoulos, 2002). To conclude, replacement of LC with WCWH in the diet of Holstein bulls did not significantly affect the rumen LCFA composition in the present study.

\section{Serum LCFA Composition}

The results of LCFA composition analysis of serum are presented in Table 7 . We observed no differences in the saturated, monounsaturated, and polyunsaturated LCFA proportions of serum among the treatments $(P$ $>0.05$ ). Our previous data revealed that replacement of LC with WCWH resulted in similar species diversity, community structure, and abundance of predominant microbes (Niu et al., 2017). Previous studies have reported that some microbes (e.g., S. bovis, B. fibrisolvens, and protozoa) participate in dietary fatty acid metabolism (Wallace et al., 1994; Makkar et al., 1998; Szkudelska et al., 2016). Therefore, we considered that the unaltered proportion of fatty acids could be attributed to similarities in rumen microbiota involved in fatty acid metabolism because these fatty acids are emptied from the rumen into the duodenum and then are absorbed into the blood (Cao et al., 2011).

Our treatment groups had no significant differences in the proportions of SFA, UFA, PUFA, n-3 FA, and n-6 FA in the serum $(P>0.05)$. Dietary UFA is beneficial for metabolizing cholesterol and removing it from the blood (Fernandez and West, 2005). Dietary SFA (particularly C16:0), along with trans isomers of UFA, induces injurious effects on cholesterol metabolism, which results in increased LDL-C concentration and reduced HDL-C concentration (Fernandez and West, 2005; Brouwer et al., 2010; Ooi et al., 2013). In contrast, dietary PUFA (particularly n-3 FA and n-6 FA) can increase HDL-C and reduce LDL-C concentrations in blood for monogastric animals and humans (Fernandez 
Table 7. Effect of dietary treatments on long-chain fatty acid composition of serum (\% of total FA)

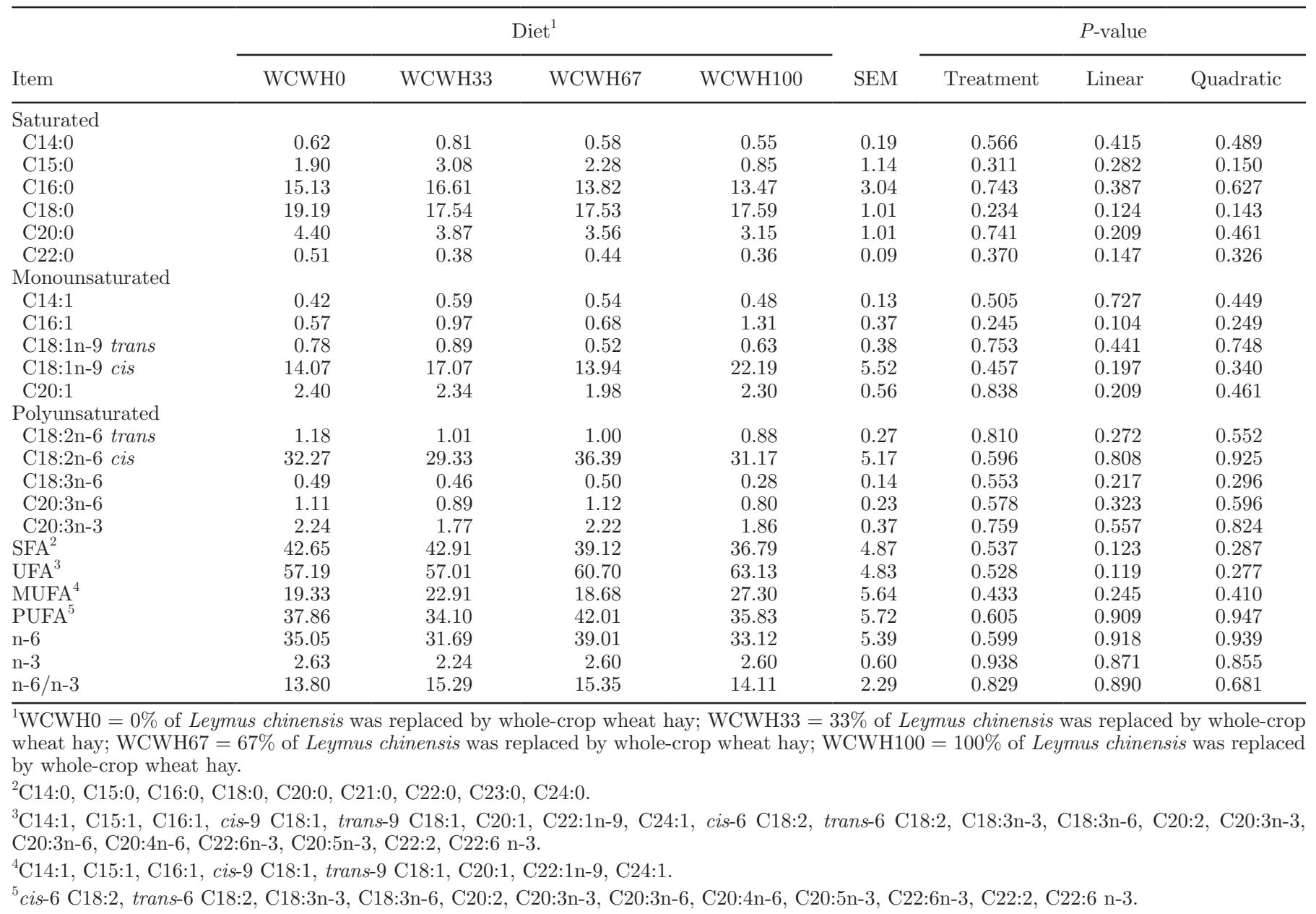

and West, 2005). For cattle, dietary PUFA undergoes biohydrogenation in the rumen; however, various factors can limit this process (Demeyer and Doreau, 1999; Petersen and Jensen, 2014). Under the circumstances, the similar degree of biohydrogenation of PUFA and SFA in the rumen among groups resulted in similar proportions of PUFA and SFA observed in the serum and therefore in similar HDL-C and LDL-C concentrations in serum. In conclusion, in Holstein bulls fed LC replaced with WCWH, there was no significant effect on the serum LCFA composition in the present research.

\section{Blood Metabolites}

The effects of our dietary treatments on serum biochemical indicators are presented in Table 8. The WCWH100 group had a greater concentration of urea nitrogen $(P<0.05)$ than the other groups. Significant linear and quadratic responses were also found in the urea nitrogen concentration among treatments groups
$(P<0.05)$. However, the treatment groups had no differences in serum glucose, triglycerides, cholesterol, total protein, albumin, HDL-C, LDL-C, and BHBA concentrations $(P>0.05)$.

Jolazadeh et al. (2015) revealed that in Holstein bulls, similar DMI resulted in no change in glucose and triglyceride concentrations in the blood. For ruminants, the primary substrate of hepatic gluconeogenesis is propionate from rumen fermentation (France and Dijkstra, 2005; Walsh et al., 2009). Our previous study has shown that replacing LC with WCWH in the diet of the Holstein bull resulted in similar DMI and ruminal propionate concentrations (Niu et al., 2017), which can be explained by similar levels of serum glucose and triglyceride in the present study. Changes in the diets did not affect the concentrations of cholesterol, HDL-C, and LDL-C in serum, which indicated no impairment of the heart and liver in Holstein bulls (Zhou et al., 2014). The similar serum cholesterol concentration is likely attributable to the similar concentrations of HDL-C and 
Table 8. Effects of different diets on serum metabolites of Holstein bulls

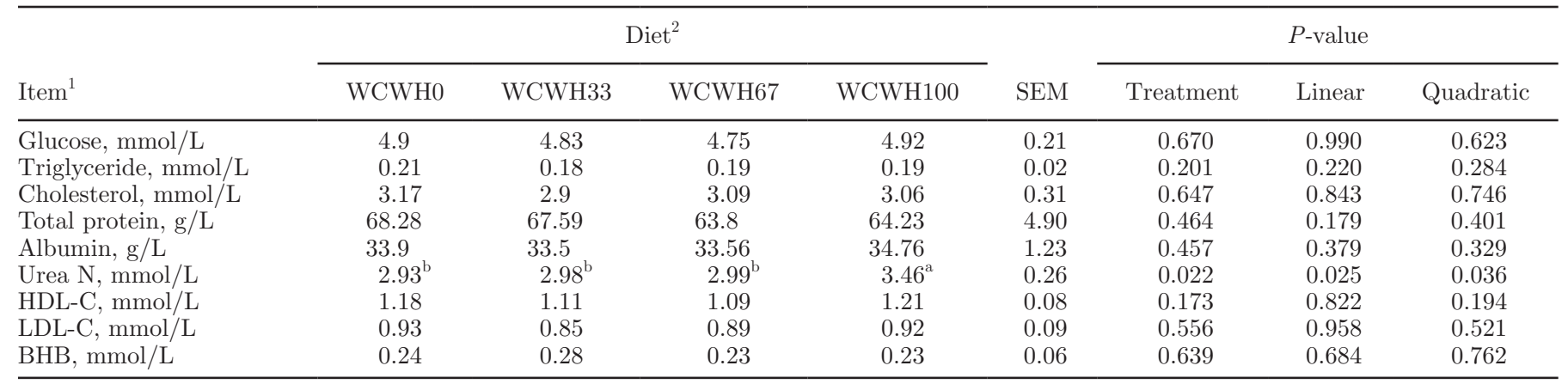

${ }_{\mathrm{a}, \mathrm{b}}$ Means within a row with different superscripts are significantly different (Tukey's test; $P<0.05$ ).

${ }^{1} \mathrm{HDL}-\mathrm{C}=$ high-density lipoprotein cholesterol; LDL-C = low-density lipoprotein cholesterol.

${ }^{2}$ WCWH0 $=0 \%$ of Leymus chinensis was replaced by whole-crop wheat hay; WCWH33 $=33 \%$ of Leymus chinensis was replaced by whole-crop wheat hay; WCWH67 $=67 \%$ of Leymus chinensis was replaced by whole-crop wheat hay; WCWH100 $=100 \%$ of Leymus chinensis was replaced by whole-crop wheat hay.

LDL-C (Szkudelska et al., 2016) because blood cholesterol is related to the concentration of HDL-C and LDL-C in cattle (Hocquette and Bauchart, 1999). The similarities in serum albumin and total protein concentrations among the dietary treatments probably were explained by the similar flow of microbial protein to the intestine (Abarghuei et al., 2014) and the amount of AA available for absorption (Min et al., 2003). The urea nitrogen is derived from AA metabolism and protein hydrolysis, and its concentration rests with the CP level (Zhou et al., 2014). As mentioned in our previous study (Niu et al., 2017), the WCWH100 group had a relatively higher protein intake, which may account for the greater serum urea nitrogen concentration compared with the other groups (Owens et al., 2009; Yang et al., 2012). In the rumen epithelium, BHBA is mostly converted by butyrate via rumen fermentation (Bergman, 1990). The undifferentiated serum BHBA levels among treatments possibly were attributable to the similar concentrations of butyrate during fermentation when the bulls were fed WCWH as a substitute for LC (Thorp et al., 2000). Taken together, these results indicate that the replacement of LC with WCWH in the diet of Holstein bulls did not significantly affect blood metabolites in our study.

\section{CONCLUSIONS}

Results from this study indicate that the use of WCWH as a substitute for LC did not negatively affect blood parameters, rumen fatty acid levels, and microbial flora composition of Holstein bulls. These results provided further confirmation and explanation of the feasibility of utilizing WCWH as forage for ruminants in the farming industry.

\section{ACKNOWLEDGMENTS}

We give special thanks to the Xinzhicheng Dairy Farm (Zhuozhou City, Hebei Province, China) for offering the experimental animals and venue. This research was funded by the National Beef Cattle Industrial Technology System (CARS-37) in Beijing, China.

\section{REFERENCES}

Abarghuei, M. J., Y. Rouzbehan, A. Z. M. Salem, and M. J. Zamiri. 2014. Nitrogen balance, blood metabolites and milk fatty acid composition of dairy cows fed pomegranate-peel extract. Livest. Sci. $164: 72-80$.

AOAC. 1990. Official Methods of Analysis. 15th ed. AOAC, Washington, DC.

Bergman, E. N. 1990. Energy contributions of volatile fatty acids from the gastrointestinal tract in various species. Physiol. Rev. 70:567-590.

Brouwer, I. A., A. J. Wanders, and M. B. Katan. 2010. Effect of animal and industrial trans fatty acids on HDL and LDL cholesterol levels in humans-A quantitative review. PLoS One 5:e9434.

Campidonico, L., P. G. Toral, A. Priolo, G. Luciano, B. Valenti, G. Hervás, P. Frutos, G. Copani, C. Ginane, and V. Niderkorn. 2016. Fatty acid composition of ruminal digesta and longissimus muscle from lambs fed silage mixtures including red clover, sainfoin, and timothy. J. Anim. Sci. 94:1550-1560.

Cao, X. Q., L. C. Liu, Y. F. Ren, and D. S. Liu. 2011. Effect of dietary supplementation of vegetable oil in equal-level of linoleic acid on fatty acid profiles in rumen and blood of sheep. Dong Bei Nong Ye Da Xue Xue Bao 42:49-54.

Chen, S., X. Huang, X. Yan, Y. Liang, Y. Wang, X. Li, X. Peng, X. Ma, L. Zhang, Y. Cai, T. Ma, L. Cheng, D. Qi, H. Zheng, X. Yang, X. Li, and G. Liu. 2013. Transcriptome analysis in sheepgrass (Leymus chinensis): A dominant perennial grass of the Eurasian Steppe. PLoS One 8:e67974.

Demeyer, D., and M. Doreau. 1999. Targets and procedures for altering ruminant meat and milk lipids. Proc. Nutr. Soc. 58:593-607.

Denman, S. E., and C. S. McSweeney. 2006. Development of a realtime PCR assay for monitoring anaerobic fungal and cellulolytic bacterial populations within the rumen. FEMS Microbiol. Ecol. 58:572-582.

Denman, S. E., N. W. Tomkins, and C. S. McSweeney. 2007. Quantitation and diversity analysis of ruminal methanogenic populations 
in response to the antimethanogenic compound bromochloromethane. FEMS Microbiol. Ecol. 62:313-322.

Fernandez, M. L., and K. L. West. 2005. Mechanisms by which dietary fatty acids modulate plasma lipids. J. Nutr. 135:2075-2078.

Fernando, S. C., H. T. Purvis, F. Z. Najar, L. O. Sukharnikov, C. R. Krehbiel, T. G. Nagaraja, B. A. Roe, and U. DeSilva. 2010. Rumen microbial population dynamics during adaptation to a highgrain diet. Appl. Environ. Microbiol. 76:7482-7490.

France, J., and J. Dijkstra. 2005. Volatile fatty acid production. Pages 157-175 in Quantitative Aspects of Ruminant Digestion and Metabolism. 2nd ed. J. Dijkstra, J. M. Forbes, and J. France, ed. CABI Publishing, Wallingford, United Kingdom.

Hocquette, J. F., and D. Bauchart. 1999. Intestinal absorption, blood transport and hepatic and muscle metabolism of fatty acids in preruminant and ruminant animals. Reprod. Nutr. Dev. 39:27-48.

Jami, E., N. Shterzer, E. Yosef, M. Nikbachat, J. Miron, and I. Mizrahi. 2014. Effects of including $\mathrm{NaOH}$-treated corn straw as a substitute for wheat hay in the ration of lactating cows on performance, digestibility, and rumen microbial profile. J. Dairy Sci. 97:1623-1633.

Janssen, P. H., and M. Kirs. 2008. Structure of the archaeal community of the rumen. Appl. Environ. Microbiol. 74:3619-3625.

Jolazadeh, A. R., M. Dehghan-Banadaky, and K. Rezayazdi. 2015. Effects of soybean meal treated with tannins extracted from pistachio hulls on performance, ruminal fermentation, blood metabolites and nutrient digestion of Holstein bulls. Anim. Feed Sci. Technol. 203:33-40.

Keady, T. W. J., F. O. Lively, D. J. Kilpatrick, and B. W. Moss. 2007. Effects of replacing grass silage with either maize or whole-crop wheat silages on the performance and meat quality of beef cattle offered two levels of concentrates. Animal 1:613-623.

Kim, S. D., and B. E. Dale. 2004. Global potential bioethanol production from wasted crops and crop residues. Biomass Bioenergy 26:361-375.

Kobayashi, Y., T. Shinkai, and S. Koike. 2008. Ecological and physiological characterization shows that Fibrobacter succinogenes is important in rumen fiber digestion-Review. Folia Microbiol. (Praha) 53:195-200.

Li, L., Y. Wang, Q. Zhang, J. Li, X. Yang, and J. Jin. 2008. Wheat straw burning and its associated impacts on Beijing air quality. Sci. China. Ser. D Earth Sci. 51:403-414.

Li, R. W., W. Li, J. Sun, P. Yu, R. L. Baldwin, and J. F. Urban. 2016. The effect of helminth infection on the microbial composition and structure of the caprine abomasal microbiome. Sci. Rep. 6:20606.

Livak, K. J., and T. D. Schmittgen. 2001. Analysis of relative gene expression data using real-time quantitative PCR and the $2^{-\Delta \Delta C} \mathrm{~T}$ method. Methods 25:402-408.

Lourenço, M., E. Ramos-Morales, and R. J. Wallace. 2010. The role of microbes in rumen lipolysis and biohydrogenation and their manipulation. Animal 4:1008-1023.

Makkar, H. P. S., S. Sen, M. Blümmel, and K. Becker. 1998. Effects of fractions containing saponins from Yucca schidigera, Quillaja saponaria, and Acacia auriculoformis on rumen fermentation. J. Agric. Food Chem. 46:4324-4328.

Mann, J., and S. Truswell. 2007. Essentials of Human Nutrition. 3rd ed. Oxford University Press, Oxford, United Kingdom.

Mc Geough, E. J., P. O'Kiely, K. J. Hart, A. P. Moloney, T. M. Boland, and D. A. Kenny. 2010. Methane emissions, feed intake, performance, digestibility, and rumen fermentation of finishing beef cattle offered whole-crop wheat silages differing in grain content. J. Anim. Sci. 88:2703-2716.

Min, B. R., T. N. Barry, G. T. Attwood, and W. C. McNabb. 2003. The effect of condensed tannins on the nutrition and health of ruminants fed fresh temperate forages: A review. Anim. Feed Sci. Technol. 106:3-19.

Moloney, A. P., M. T. Mooney, J. P. Kerry, C. Stanton, and P. O'Kiely. 2013. Colour of fat, and colour, fatty acid composition and sensory characteristics of muscle from heifers offered alternative forages to grass silage in a finishing ration. Meat Sci. 95:608-615.
Nagaraja, T. G., and E. C. Titgemeyer. 2007. Ruminal acidosis in beef cattle: The current microbiological and nutritional outlook. J. Dairy Sci. 90(Suppl. 1):E17-E38.

Niu, W., Y. He, C. Xia, M. A. U. Rahman, Q. Qiu, T. Shao, Y. Liang, L. Ji, H. Wang, and B. Cao. 2017. Effects of replacing Leymus chinensis with whole-crop wheat hay on Holstein bull apparent digestibility, plasma parameters, rumen fermentation, and microbiota. Sci. Rep. 7:2114.

NRC. 2000. Nutrient Requirements of Beef Cattle. 7th ed. Natl. Acad. Sci., Washington, DC.

Ooi, E. M., T. W. Ng, G. F. Watts, and P. H. Barrett. 2013. Dietary fatty acids and lipoprotein metabolism: New insights and updates. Curr. Opin. Lipidol. 24:192-197.

Owens, D., M. McGee, T. Boland, and P. O'Kiely. 2009. Rumen fermentation, microbial protein synthesis, and nutrient flow to the omasum in cattle offered corn silage, grass silage, or whole-crop wheat. J. Anim. Sci. 87:658-668.

Owens, F. N., D. S. Secrist, W. J. Hill, and D. R. Gill. 1998. Acidosis in cattle: A review. J. Anim. Sci. 76:275-286.

Petersen, M. B., and S. K. Jensen. 2014. Biohydrogenation of fatty acids is dependent on plant species and feeding regimen of dairy cows. J. Agric. Food Chem. 62:3570-3576.

Shi, H., and P. Yu. 2017. Comparison of grating-based near-infrared (NIR) and Fourier transform mid-infrared (ATR-FT/MIR) spectroscopy based on spectral preprocessing and wavelength selection for the determination of crude protein and moisture content in wheat. Food Contr. 82:57-65.

Shi, H. T., S. L. Li, Z. J. Cao, Y. J. Wang, G. M. Alugongo, and P. H. Doane. 2015. Effects of replacing wild rye, corn silage, or corn grain with CaO-treated corn stover and dried distillers grains with solubles in lactating cow diets on performance, digestibility, and profitability. J. Dairy Sci. 98:7183-7193.

Simopoulos, A. P. 2002. Omega-3 fatty acids in inflammation and autoimmune diseases. J. Am. Coll. Nutr. 21:495-505.

The State Science and Technology Commission. 1988. Regulations for the Administration of Affairs Concerning Experimental Animals. P. R. China.

Stevenson, D. M., and P. J. Weimer. 2007. Dominance of Prevotella and low abundance of classical ruminal bacterial species in the bovine rumen revealed by relative quantification real-time PCR. Appl. Microbiol. Biotechnol. 75:165-174.

Sylvester, J. T., K. R. Karnati, Z. Yu, M. Morrison, and J. L. Firkins. 2004. Development of an assay to quantify rumen ciliate protozoal biomass in cows using real-time PCR. J. Nutr. 134:3378-3384.

Szkudelska, K., M. Szumacher-Strabel, J. Szczechowiak, M. Bryszak, E. Pers-Kamczyc, A. Stochmal, and A. Cieslak. 2016. The effect of triterpenoid saponins from Saponaria officinalis on some blood hormones, metabolic parameters and fatty acid composition in dairy cows. J. Agric. Sci. 154:532-541.

Talebnia, F., D. Karakashev, and I. Angelidaki. 2010. Production of bioethanol from wheat straw: An overview on pretreatment, hydrolysis and fermentation. Bioresour. Technol. 101:4744-4753.

Thorp, C. L., A. Wylie, R. Steen, C. Shaw, and J. D. Mcevoy. 2000. Effects of incremental changes in forage:concentrate ratio on plasma hormone and metabolite concentrations and products of rumen fermentation in fattening beef steers. J. Anim. Sci. 71:93-109.

Toral, P. G., G. Hervás, E. Bichi, Á. Belenguer, and P. Frutos. 2011. Tannins as feed additives to modulate ruminal biohydrogenation: Effects on animal performance, milk fatty acid composition and ruminal fermentation in dairy ewes fed a diet containing sunflower oil. Anim. Feed Sci. Technol. 164:199-206.

Van Soest, P. J., J. B. Robertson, and B. A. Lewis. 1991. Methods for dietary fiber, neutral detergent fiber, and nonstarch polysaccharides in relation to animal nutrition. J. Dairy Sci. 74:3583-3597.

Wallace, R. J., L. Arthaud, and C. J. Newbold. 1994. Influence of Yucca shidigera extract on ruminal ammonia concentrations and ruminal microorganisms. Appl. Environ. Microbiol. 60:1762-1767.

Walsh, K., P. O. Kiely, H. Z. Taweel, M. McGee, A. P. Moloney, and T. M. Boland. 2009. Intake, digestibility and rumen characteristics 
in cattle offered whole-crop wheat or barley silages of contrasting grain to straw ratios. Anim. Feed Sci. Technol. 148:192-213.

Weinberg, Z. G., and Y. Chen. 2013. Effects of storage period on the composition of whole crop wheat and corn silages. Anim. Feed Sci. Technol. 185:196-200.

Whitelaw, F. G., J. M. Eadie, L. A. Bruce, and W. J. Shand. 1984 Methane formation in faunated and ciliate-free cattle and its relationship with rumen volatile fatty acid proportions. Br. J. Nutr. $52: 261-275$.

Wilde, P. F., and R. M. Dawson. 1966. The biohydrogenation of alphalinolenic acid and oleic acid by rumen micro-organisms. Biochem. J. 98:469-475.

Wood, T. M., C. A. Wilson, and C. S. Stewart. 1982. Preparation of the cellulase from the cellulolytic anaerobic rumen bacterium Ruminococcus albus and its release from the bacterial cell wall. Biochem. J. 205:129-137.

Yan, R., S. Chen, X. Zhang, J. Han, Y. Zhang, and D. Undersander. 2011. Short communication: Effects of replacing part of corn silage and alfalfa hay with Leymus chinensis hay on milk production and composition. J. Dairy Sci. 94:3605-3608.

Yang, W. Z., Y. L. Li, T. A. McAllister, J. J. McKinnon, and K. A. Beauchemin. 2012. Wheat distillers grains in feedlot cattle diets: Feeding behavior, growth performance, carcass characteristics, and blood metabolites. J. Anim. Sci. 90:1301-1310.

Zhang, T. T., G. Y. Zhao, W. S. Zheng, W. J. Niu, and C. Wei. 2015. Effects of rare earth element lanthanum on rumen methane and volatile fatty acid production and microbial flora in vitro. J. Anim. Physiol. Anim. Nutr. (Berl.) 99:442-448.

Zhou, Z., B. Zhou, L. Ren, and Q. Meng. 2014. Effect of ensiled mulberry leaves and sun-dried mulberry fruit pomace on finishing steer growth performance, blood biochemical parameters, and carcass characteristics. PLoS One 9:e85406.

Zhu, W., Y. Fu, B. Wang, C. Wang, J. A. Ye, Y. M. Wu, and J. X. Liu. 2013. Effects of dietary forage sources on rumen microbial protein synthesis and milk performance in early lactating dairy cows. J Dairy Sci. 96:1727-1734. 